\title{
DISCURSOS POLÍTICOS ANTE LA CRISIS ECONÓMICA: ESTUDIO DEL LÍDER DEL PSOE
}

\author{
POLITICAL DISCOURSES IN ECONOMIC CRISIS: STUDY OF PSOE'S \\ LEADER
}

\author{
Francisco Collado Campaña \\ José Francisco Jiménez Díaz \\ Universidad Pablo de Olavide, Sevilla. España/Spain \\ f collado c@hotmail.com \\ josefco@,upo.es
}

Recibido/Received: 03/06/2012

Modificado/Modified: 28/09/2012

Aceptado/Accepted: 12/10/2012

\section{RESUMEN}

La crisis económica es una realidad compleja que experimentan distintos países de la Unión Europea. Y es que, debido a sus consecuencias, especialmente el paro y el aumento del déficit público, distintos países han tenido que recurrir al rescate financiero. En el presente trabajo, se analiza el lenguaje político del Presidente del Gobierno de España durante los inicios de la crisis en 2008, para observar la evolución del liderazgo y del discurso de José Luis Rodríguez Zapatero desde la perspectiva del constructivismo estructuralista.

\section{PALABRAS CLAVE}

Crisis, lenguaje político, liderazgo, Zapatero, análisis biográfico.

\section{SUMARIO}

1. Introducción: el estudio del discurso político. 2. Objetivos y metodología. 3. Contexto sociopolítico y liderazgo de Rodríguez Zapatero ante la crisis. 4. La gestión del lenguaje al inicio de la crisis, un enfoque discursivo. 4.1. Hablando de economía: una visión cuantitativa. 4.1.1. La intencionalidad del discurso: midiendo la intención del orador. 4.1.2. La gestión de los temas: la configuración de la agenda a través del discurso. 4.2. Una visión cualitativa del discurso destinado a economía. 4.2.1. El framing en la agenda del PSOE para las elecciones de 2008. 4.2.2. La subjetividad y las estrategias discursivas en el Discurso de Investidura. 4.2.3. El framing del líder en el Plan E. 5. Apuntes constructivistas sobre el líder y su discurso ante la crisis. 6 . Bibliografía.

\footnotetext{
ABSTRACT

The economic crisis is a very complex reality that experience different countries of the European Union. And it is that, because of its consequences, especially the unemployment and the increase of the public deficit, distinct countries have had to resort to the financial rescue. In the present work, we analyse the political language of the President of the Government of Spain during the starts of the crisis in 2008, to observe the evolution of the leadership and of the speech of José Luis Rodríguez Zapatero from the constructivism.
} 


\section{KEYWORDS}

Crisis, political language, leadership, Zapatero, biographical analysis.

\section{CONTENTS}

1. Introduction: the study of political discourse. 2. Goals and methodology. 3. Socio-political context and Rodríguez Zapatero's leadership in the crisis. 4. The managing of language at the beginning of the crisis, a discursive approach. 4.1. Speaking of economy: a quantitative view. 4.1.1. The intentionality of the speech: measuring the speaker's intention. 4.1.2. Managing issues: setting the agenda through discourse. 4.2. A qualitative perspective on the economic discourse. 4.2.1. The framing in the agenda of the PSOE for the 2008 elections. 4.2.2. The subjectivity and the discursive strategies in the Speech of Investiture. 4.2.3. The framing of leader in the E Plan. 5. Constructivist perspective on leader and his speech to the crisis. 6 . References.Introduction. 2. Reflections and analysis on the economic and social crisis and its impact on human mobility. 3. Immigration, crisis and media. 4. The social integration of immigrants in Spain in crisis time. 5. Conclusions. References.

\section{INTRODUCCIÓN}

\section{El estudio del discurso político}

El lenguaje político constituye una herramienta fundamental en el desarrollo de la vida pública. Los representantes políticos emplean diariamente este lenguaje sectorial, en tanto que los primeros se constituyen en políticos profesionales. Los discursos en las asambleas representativas y dentro de los partidos políticos ilustran algunas de las manifestaciones de esta modalidad discursiva vinculada al poder. Desde la transición a la democracia en España, han sido numerosos los estudios sobre lenguaje político. Las investigaciones desarrolladas por Alvar (1987), Del Águila y Montoro (1984), Fernández (1999), Guitart (2006), Núñez y Guerrero (2002) y De Miguel (1985), entre otros, demuestran un claro intento de estudiar el lenguaje político español.

El análisis lingüístico del discurso político se ha desarrollado interdisciplinarmente. Así, este análisis se ha enriquecido con las aportaciones de las Ciencias de la Comunicación, los Estudios Culturales, la Psicología Cognitiva y la Sociología. Entre tales aportaciones, destacan las de Goffman (1974), Martín (1998), Van Dijk (1999), Lakoff (2007), Chilton y Schäffner (2003), así como enfoques sociológicos que aportan nuevos marcos analíticos desde los que estudiar las relaciones entre discurso y liderazgo político. Uno de esos enfoques es el "estructuralismo constructivista" (Bourdieu, 1988), que en este trabajo se aplica al estudio de las relaciones entre el lenguaje político -concibiéndolo integrado en el "habitus" del líder- y el liderazgo ejercido en el "campo político" (Jiménez, 2008).

Sin duda, los actores políticos en sus luchas por el poder, las configuraciones políticoinstitucionales y las circunstancias de cada momento condicionan las características y mudanzas del lenguaje político. De hecho, este lenguaje no se puede analizar sin considerar el complejo y cambiante contexto en que se inserta. Por ello, la crisis económica y financiera ofrece un escenario único para investigar el papel que cumple el lenguaje de la clase política. Este escenario contribuye a hacer preguntas como las siguientes: ¿cuáles son los rasgos del lenguaje político en la crisis?, o bien, ¿qué posibilidades ofrece el discurso a los líderes en esta situación? 


\section{OBJETIVOS Y METODOLOGÍA}

Desde hace cinco años, la economía española experimenta una crisis profunda debido al desplome del modelo económico basado en el sector inmobiliario y la especulación financiera. A finales del año 2007, surgieron los primeros síntomas de lo que se ha denominado como "Gran Recesión" (Estefanía, 2009). Así, durante los años 2008 y 2009, aumentó el desempleo, la inflación, la deuda pública y el déficit público, lo cual conllevó una intensa crisis financiera y económica. En los últimos tres años, esta negativa situación se ha agravado hasta el punto de que la tasa de paro en España supera el 24\% y la deuda pública ha aumentado sin cesar. Ello conlleva el incumplimiento de los objetivos macroeconómicos impuestos por la Unión Europea, el descrédito internacional y el creciente encarecimiento de la financiación del Estado español.

Este escenario conforma unas nuevas y complejas circunstancias para los discursos de los líderes políticos. Por ello, los estudios sobre liderazgo político han de abordar un interrogante crucial. ¿Cómo desarrollan los líderes políticos sus discursos durante las crisis económicas? De este modo, el presente análisis indaga en cuáles han sido las características del lenguaje político empleado por José Luis Rodríguez Zapatero ante la realidad económica del comienzo de su segundo mandato (2008-2011). Asimismo, en este trabajo se pretende conocer si el deterioro económico iniciado en 2008 influyó en el discurso y liderazgo político del Presidente del Gobierno. Por un lado, se desestima el análisis del lenguaje político a partir de la información de prensa debido al sesgo del proceso de construcción del mensaje periodístico. Por otro, tampoco se consideran los mítines políticos realizados en calidad de líder del PSOE, debido a que no actúa como Jefe del Gobierno. Por tanto, aquí se estudia un texto estrictamente público como es el Discurso de Investidura de 2008.

Así, el presente análisis profundiza en el mensaje sobre la situación económica en el Discurso de Investidura del Presidente del Gobierno. Para enmarcar su configuración sociolingüística se ha tomado como referencia un discurso anterior, el programa electoral del PSOE en las Elecciones Generales de 2008, así como un texto posterior, concretamente el contenido del Plan Español para el Estímulo de la Economía y el Empleo (Plan E). De esta manera, se delimitan varios marcos (frames) asociados a dicho Discurso (Goffman, 1974).

El carácter poliédrico de esta realidad política y económica lleva a efectuar un uso combinado de las metodologías de la lingüística y la sociología política. Así, este análisis se bifurca en la vertiente sociopolítica orientada al estudio del líder y en la vertiente sociolingüística destinada al análisis del discurso (Collado y Jiménez, 2009). Primero, se estudia el liderazgo de Rodríguez Zapatero mediante el análisis biográfico y de su contexto sociopolítico, por lo que se pretende conocer el "habitus" y el "campo político" de este líder (Jiménez, 2008). Luego, se procede al análisis sociolingüístico que permite revelar cuáles son las intenciones y herramientas del lenguaje esgrimidas por Rodríguez Zapatero. Por ello, el análisis del discurso se compone de un recuento cuantitativo de las funciones lingüísticas (Collado y Jiménez, 2009) y los "temas políticos" (Lindblom y Woodhouse, 1993), un estudio cualitativo donde se interrelacionan los rasgos del lenguaje político (Núñez, 2002; Alvar, 1987; Fernández, 1999) y los recursos retóricos (Lausberg, 1991; López, 2000) con el "habitus" y el campo político del líder (Bourdieu, 1988; Jiménez, 2008), así como con el marco, discurso legítimo y censura estructural (Goffman, 1974; Martín, 1998). Por último, se procede a interrelacionar estos elementos para disponer de una visión global del discurso político, pues éste se configura como un acto lleno de coherencia para realizar la voluntad del líder (López, 2000:177-178). 


\section{CONTEXTO SOCIOPOLÍTICO Y LIDERAZGO DE RODRÍGUEZ ZAPATERO ANTE LA CRISIS}

Es evidente que la crisis económica ha constituido una importante prueba para el liderazgo político de José Luis Rodríguez Zapatero, así como para el liderazgo de otros líderes nacionales e internacionales (Rajoy, Rubalcaba, Obama, Hollande, Merkel, Monti, etc.). Por ello, dependiendo de cómo los líderes gestionen las crisis económicas podrán reforzar o debilitar sus respectivos liderazgos y la confianza que en ellos depositan los ciudadanos.

En la práctica, se puede decir que no se conoce realmente al gobernante hasta que no se dispone a abordar una crisis. Además, el liderazgo es un fenómeno complejo, multidimensional y envuelto en un proceso de construcción social (Burns, 1978; Berger y Luckmann, 1997; Grint, 2005; Robles, 2009). Así, todo liderazgo político se construye en un contexto social, político y personal concreto. En ese contexto el líder se socializa, resocializa y aprehende su particular lenguaje político. Por ello, el análisis biográfico de los líderes es una herramienta útil para conocer sus habitus: modos de percibir, nombrar, creer y valorar la realidad (Jiménez, 2008). Dicho de otra forma, el habitus es la manera en que cada individuo incorpora y reconstruye la realidad social a partir de su propia subjetividad o fuero interno.

En el año 2010, cuando los efectos de la crisis financiera y económica eran notorios en España y en Europa, el ex-presidente del Gobierno Felipe González reclamaba un habitus renovado en los líderes para afrontar la crisis: "Si no decimos con claridad las cosas, no nos van a creer y el debate seguirá siendo defensivo e inoperante [...] La opinión pública va a agradecer a los líderes que le ofrezcan un proyecto coherente, con un diagnóstico sin concesiones de lo que nos pasa y una voluntad de diálogo que sume a todos" (González, 2010:12-20).

En efecto, cuando los liderazgos políticos viven bajo la presión y los efectos de una crisis tan grave y profunda como la presente, han de abordar diversas tareas para ofrecer un relato creíble sobre la crisis y de sus posibles salidas; esto es, deben proporcionar sentido, adoptar decisiones, ofrecer significado y aprender de la crisis (Boin et al, 2007:29) para tratar de que no se repita. Así, los líderes en las democracias se ven obligados a transformar sus habitus y lenguajes políticos con el devenir de las crisis.

En ese sentido, la vida política española del último quinquenio no se comprende sin conocer los efectos que sobre ella ha tenido la crisis económica. Los efectos de ésta sobre los liderazgos políticos han sido muy diversos dependiendo de la situación de cada país y de cada líder, pero, sin duda, las nefastas consecuencias de la crisis han desgastado la credibilidad y la confianza depositada por los ciudadanos en muy distintos gobiernos de toda Europa. Así sucedió con el último gobierno liderado por José Luis Rodríguez Zapatero, entre los años 2008 y 2011. El líder del PSOE tardó casi un año en reconocer la gravedad de la crisis y aún más tiempo en empezar a tomar medidas. Si bien, las primeras medidas desarrolladas por el gobierno de Zapatero se correspondían, más o menos, con su discurso político y algunas de las promesas electorales de 2008 (Plan E), la política económica que impulsó el gobierno socialista a partir del mes de mayo de 2010 empezó a contradecir radicalmente el discurso socialdemócrata y a promover medidas ortodoxas propuestas desde la Unión Europea, pese a ser consciente del alto coste político que tendría su cambio de posición. En el Debate sobre el Estado de la Nación de 2010, el Presidente del Gobierno afirmó lo siguiente: "Tomaré las decisiones que España necesita aunque sean 
difíciles. Voy a seguir ese camino cueste lo que cueste y me cueste lo que me cueste" (Rodríguez Zapatero citado en Garea, 2010).

Por tanto, como resultado de la contradicción de su propio discurso político y de la impopularidad de las medidas económicas adoptadas, la credibilidad de Rodríguez Zapatero y, en consecuencia, su liderazgo político experimentó un notable proceso de decadencia y de cuestionamiento interno en su partido que lo llevó al límite en el ejercicio de las tareas de gobierno (Jiménez y Collado, 2011:147-151). Así, el PSOE perdió varias elecciones en 2011 (Locales, Autonómicas y Generales) como resultado del enorme desgaste experimentado por Rodríguez Zapatero y del "vaciado" ideológico que el líder leonés tuvo que hacer en el PSOE para adoptar las nuevas medidas económicas de austeridad (Álvarez, 2011). Dicho vaciado ideológico y el cambio de discurso político que conllevó provocaron que muchos votantes socialistas se abstuvieran o votaran a otras opciones políticas, de modo que en las Elecciones Generales de 2011 el PSOE obtuvo el peor resultado de las últimas tres décadas. Por tanto, el habitus del Presidente del Gobierno (su forma de incorporar y reconstruir la realidad sociopolítica) se transformó notoriamente durante la crisis. De hecho, su posición ideológica y discursiva se enfrentó al dilema entre las aspiraciones y la realidad.

Algunos estudios atribuyen a Rodríguez Zapatero las siguientes características: un profundo sentido del deber, es calculador y de carácter frío en los quehaceres de la vida política (De Toro, 2007), "no derrocha afectos ni confidencias" (García Abad, 2010:28), escucha más que habla, permanece ajeno a las influencias externas en el cargo de la Presidencia del Gobierno, se orienta por el bien común y la paz. Debido a este carácter algunos dicen que el referido líder posee madera de presidente (De Toro, 2007). Una perspectiva parecida a la anterior se halla en otros trabajos biográficos y políticos sobre la figura del ex-presidente Rodríguez Zapatero; bien destacando su trayectoria humana y política (Campillo, 2004); o bien revelando su resuelta y estratégica visión para alcanzar y mantener el poder político (Campmany, 2005; García Abad, 2010; Valenzuela, 2007). En concreto, el trabajo de Campmany ilustra como el líder es capaz de convertirse en una marca y comercializarse en manos de la mercadotecnia electoral bajo la "campaña ZP”. Otros analistas se han referido a la figura de Zapatero como un líder poco riguroso en el uso de su lenguaje y pensamiento político, tendente a la excesiva simplificación (Bueno, 2006: 356). Para contrastar afirmaciones tan dispares es conveniente analizar la trayectoria biográfica del expresidente del Gobierno y, así, observar sus cualidades políticas.

La trayectoria biográfica de Zapatero muestra a un líder que, desde muy joven, ha acumulado un gran capital político y que se ha adaptado a muy diversas circunstancias sociopolíticas durante su carrera. Se ha dicho que es un "verdadero político profesional" y que para él "la política no es solo una responsabilidad ni un oficio, sino la vida misma" (García Abad, 2010:17-25). De hecho, Rodríguez Zapatero hizo de la política su principal medio de vida desde muy joven, lo que le llevó a acumular un valioso capital político dentro del Partido Socialista Obrero Español (PSOE), entendiendo dicho capital como un conjunto de recursos personales, sociales y posiciones político-institucionales que aproximan al poder político.

En ese sentido, combinó su presencia en el ámbito político local y nacional desde muy joven, si bien para dicho líder fue decisivo alcanzar el acta de diputado nacional en 1986, ya que su vida política en León estaba orientada a cumplir al menos este objetivo. Así, Zapatero recorrió una sorprendente carrera que le permitió pasar desde la arena política local y provincial hasta la nacional, ejerciendo diferentes cargos, entre los que destaca el haber sido el diputado más joven en la tercera legislatura democrática (1986-1989), hasta llegar a ocupar la 
Secretaría General del PSOE en el año 2000 y, poco más tarde, la Presidencia del Gobierno de España en las primeras elecciones a las que se presentó (Jiménez y Collado, 2011).

$\mathrm{Su}$ liderazgo ha sido moderado, conciliador, dialogante, firme y comprometido moralmente con ciertos valores de su programa político, al tiempo que la dimensión internacional de su figura política ha sido escasa. Por tanto, su liderazgo se fundamenta en la negociación y en la transacción, que consiste en el constante intercambio entre líder y seguidores para aproximar necesidades recíprocas y deseos. Este tipo de liderazgo persigue valores como la sinceridad, honestidad y la responsabilidad (Burns, 1978). Una cualidad moral que resalta en su carrera política es su fidelidad a los principios políticos y éticos de un socialismo fundado en la libertad (Campillo, 2004:29). Zapatero expone que socialismo es libertad y que: "la libertad es el camino de la igualdad, porque sin la libertad, que es la expresión de la democracia, no hay igualdad” (De Toro, 2007:210).

En el campo ideológico ha sido denominado como "demócrata social" más que socialdemócrata. Respecto a su posición ideológica Zapatero argumentó que: "La izquierda tal y como yo la entiendo, tiene una parte importante de socialdemocracia. La diferencia es que en la socialdemocracia tradicional pesaba más lo social y en la izquierda moderna lo democrático tiene que pesar tanto como lo otro" (De Toro, 2007:186-187). Así, la ideología del citado líder se caracteriza por un socialismo pragmático, deudor de muchos de los principios del liberalismo en lo económico, pues "el criterio de no dominación en el ámbito económico - esto es, como ausencia de interferencia arbitraria- adquiere mayor flexibilidad y no supone un cuestionamiento central de la economía de mercado, sino de algunas de sus consecuencias más extremas" (García Agustín, 2006:19). Por ello, durante la gestión de la crisis económica española, y a medida que ésta se fue agravando, el líder del PSOE fue incorporando algunos argumentos neoliberales en los temas económicos, incluso sacrificando algunas conquistas sociales abanderadas por la socialdemocracia, sobre todo desde mayo de 2010 (Pano, 2011).

Por consiguiente, como se ha advertido más arriba y se comprobará más adelante, el modo de abordar la crisis económica en sus discursos y las diversas medidas económicas asociadas a tales discursos cambiaron la posición discursiva de Rodríguez Zapatero. Este cambio generó un notable deterioro del liderazgo de Rodríguez Zapatero y declive de la imagen pública del Partido Socialista Obrero Español (PSOE).

\section{LA GESTIÓN DEL LENGUAJE AL INICIO DE LA CRISIS, UN ENFOQUE DISCURSIVO}

La elección del Discurso de Investidura (Rodríguez Zapatero, 2008) como documento central del presente trabajo reside en dos motivos. En primer lugar, representa el texto más significativo que recoge el programa político del ejecutivo en los inicios de la crisis económica que había empezado a afectar a España. Por otro, permite observar el planteamiento inicial que presentaba la política económica y financiera de España en la agenda pública, así como la aparición de la "crisis" como un problema político.

\subsection{Hablando de economía: una visión cuantitativa}

4.1.1. La intencionalidad del discurso: midiendo la intención del orador

En primer lugar, se ha procedido a la contabilización porcentual de las funciones lingüísticas empleadas en el área del Discurso de Investidura que se dedica a economía 
según la cantidad de frases. Así, cada proposición central dedicada a economía ha sido la unidad de la que se ha partido para clasificar cada función.

Por tanto, un primer paso ha consistido en contabilizar el total de proposiciones centrales de este documento, unas 336 en total, de las que 162 corresponden con el espacio dedicado a materia económica. Es necesario apuntar que para la contabilización del área destinada a economía, el presente estudio no se limita a los epígrafes que aporta el documento del Discurso de Investidura. Muy al contrario, se considera un concepto amplio del issue "economía", lo que también incluye cuestiones como política social, fiscal, comercial y financiera por la repercusión que tienen en dicha materia. Además, es interesante observar como en torno a un 48,21\% representa el porcentaje del discurso dedicado a dicho tema. Este porcentaje confirma que la preocupación por el desarrollo de la economía española, que es el tema que introduce el discurso, ha sido el principal "issue" para el líder político. En la siguiente tabla se presentan los resultados de la contabilización efectuada.

Tabla 1. Funciones lingüísticas en el área dedicada a economía.

\begin{tabular}{|l|c|c|}
\hline FUNCIÓN & PROPOSICIONES & PORCENTAJE \\
\hline Referencial / Informativa & 82 & $50,61 \%$ \\
\hline Emotiva / Expresiva & 30 & $18,31 \%$ \\
\hline Fática & 4 & $2,40 \%$ \\
\hline Conativa & 41 & $25,30 \%$ \\
\hline Poética & 3 & $1,85 \%$ \\
\hline Metalingüística & 2 & $1,23 \%$ \\
\hline
\end{tabular}

Fuente: elaboración propia

Si se observan los anteriores datos, la función primordial del discurso económico de Rodríguez Zapatero ha consistido en transmitir información $(50,61 \%)$, datos y cifras sobre la situación económica, las actuaciones y los proyectos a realizar durante la nueva legislatura en esta materia. Desde el constructivismo, se interpreta una visión aséptica del problema en cuestión, abundando las expresiones propias del lenguaje macroeconómico. De entrada, esta evidencia previa lleva a hablar de un lenguaje administrativo debido a que existe una lógica política de resolución de problemas asumida por parte del líder, muy centrada en asuntos de gestión e implementación pública. Ello, probablemente, permita hablar de un perfil "administrador" en el habitus de Zapatero. Un habitus que ha obtenido de su dilatada experiencia en el campo político desde su llega al Congreso de los Diputados (1986).

Después de la función referencial, las más habituales la representan la conativa y la emotiva, lo que aporta una información adicional. Por un lado, es frecuente que en el lenguaje político exista una primacía de la función conativa o apelativa, destinada a convencer y a obtener una respuesta favorable de la audiencia. Este fenómeno, conocido como "lenguaje totalitario" (García, 1987:90-92), no se cumple necesariamente en este discurso como evidencian los datos. Concretamente, esta excepción general a la regla es lo que permite hablar de Zapatero como un líder negociador y abierto a la transacción, es decir, en términos sociolingüísticos no cumple con el perfil del orador político tradicional, más caracterizado por la unilateralidad (véase, Bühler, Van Dijk y Alvar). 
Pese a ello, esta función representa la segunda más utilizada con un 25,30\% del espacio. En ese sentido, el mensaje de Zapatero ha pasado de unas altas dosis de información laxa a la aportación de argumentos y razones para sostener sus posturas, más polémicas y divergentes entre la ciudadanía. Así, en materias como inmigración, derechos y políticas sociales ha sido necesario reafirmar las actuaciones del nuevo Gobierno porque representan puntos de fricción no consensuados en los distintos contextos sociales que conforman la sociedad española. En términos sociopolíticos se observa a un líder que emplea la función conativa para imponer su habitus en torno al tema de la inmigración en el campo de lo social, por ejemplo. Así, el lenguaje es la herramienta del habitus del líder para conciliar su postura en el campo político y obtener el capital simbólico que representa el respaldo de la opinión pública.

En cuanto a la función emotiva o expresiva, se muestra como el orador recurre a ella para completar su uso de la conativa, pues los sentimientos y las convicciones personales cubren las áreas de conflicto. Al respecto, pueden señalarse determinadas partes del discurso donde escasea la función informativa, pero abunda el recurso a la función apelativa en combinación con el apoyo en la expresiva. En otras palabras, el líder tiende a apoyar su mensaje mediante el recurso a argumentos convincentes que se sustentan en sus ideas, sentimientos y emociones. Por tanto, se halla a un líder que recurre a la emotividad y la sensibilidad en asuntos concretos donde se produce un disenso social. En otras palabras, la apuesta por determinadas decisiones conflictivas y no consensuadas pasa por la influencia en el ámbito de los sentimientos y la emotividad de los ciudadanos.

Posteriormente, la función fática ocupa un lugar residual, destinada tan sólo a efectuar algunas introducciones del discurso y a comprobar la atención mantenida por la audiencia. Las referencias a las funciones metalingüística y poética son anecdóticas, representando ambas una cuota inferior al 5\%.

Por tanto, el lenguaje político de Zapatero y su perfil político en este mensaje resultan inusuales para los anteriores líderes que han pasado por el Gobierno de España, tales como José María Aznar y Felipe González (en ambos se observaba la primacía de la función apelativa, propia de líderes poco dispuestos a la negociación). Frente al anterior presidente socialista, marcado por un liderazgo transformador, ortodoxo y desligado de su programa político (Jiménez, 2009), Zapatero muestra un perfil más burocrático, ceñido a los objetivos programáticos. En cambio, otros líderes como Adolfo Suárez y Felipe González presentaban un discurso más cercano a la función emotiva. Al no primar la función emotiva tanto como la informativa, queda la primera relegada a un segundo plano al abordar la situación económica. De ahí, que se pueda calificar de un discurso hasta cierto punto transaccional y negociable, debido a la limitación que imponen las convicciones del líder como frontera para hacer política. Así, el recurso a la expresión de sus valores, sus convicciones morales y sus ideas suponen un intento de completar aquellas posibles lagunas que el líder ha considerado que no quedan adecuadamente legitimadas mediante la aportación de argumentos con la función conativa. En otras palabras, y de acuerdo al planteamiento del sujeto estudiado, incluso en una situación económica difícil deberían primar los derechos y los valores frente a cualquier esfuerzo de la ciudadanía que pueda plantearse como ineludible.

Por tanto, este recurso discursivo implica un intento de transmisión a la audiencia de su forma de percibir, valorar y denominar la realidad. Y ello demuestra cierta independencia del líder respecto a las discrepancias que puedan surgir en el campo político donde se desenvuelve el Discurso de Investidura. De este modo, aunque el habitus pueda parecer conciliador y transaccional, existe un mínimo común político que el gobernante no está 
dispuesto a ceder: los derechos sociales. Ello está vinculado a su ideología política, como se expondrá más adelante.

Tabla 2. Temas en relación al área destinada a economía y la totalidad del discurso

\begin{tabular}{|l|c|c|c|}
\hline \multicolumn{1}{|c|}{ Temas } & Proposiciones & $\begin{array}{c}\text { Porcentaje/ } \\
\text { Economía }\end{array}$ & $\begin{array}{c}\text { Porcentaje } \\
\text { total }\end{array}$ \\
\hline Agricultura & 1 & $0,61 \%$ & $0,29 \%$ \\
\hline Ayudas sociales y pensiones & 34 & $20,98 \%$ & $10,11 \%$ \\
\hline Construcción & 14 & $8,64 \%$ & $4,16 \%$ \\
\hline Crecimiento económico & 37 & $22,83 \%$ & $11,01 \%$ \\
\hline Recesión económica & 31 & $19,13 \%$ & $9,22 \%$ \\
\hline Empleo & 28 & $17,28 \%$ & $8,33 \%$ \\
\hline Financiación de las autonomías & 12 & $7,40 \%$ & $3,57 \%$ \\
\hline Igualdad laboral de géneros & 17 & $10,49 \%$ & $5,05 \%$ \\
\hline Industria & 25 & $15,43 \%$ & $7,44 \%$ \\
\hline Inflación & 6 & $3,70 \%$ & $1,78 \%$ \\
\hline Inmigración & 21 & $12,96 \%$ & $6,25 \%$ \\
\hline Investigación y Desarrollo (I+D) & 23 & $14,19 \%$ & $6,84 \%$ \\
\hline Ley de Dependencia & 5 & $3,08 \%$ & $8,03 \%$ \\
\hline Política fiscal & 27 & $16,66 \%$ & $8,03 \%$ \\
\hline Política presupuestaria & 52 & 32,09 & $15,47 \%$ \\
\hline Política social & 85 & $52,46 \%$ & $25,29 \%$ \\
\hline Productividad y competencia & 34 & $20,98 \%$ & $10,11 \%$ \\
\hline Salarios & 8 & $4,93 \%$ & $2,38 \%$ \\
\hline Sociedad de la Información y el & 16 & $9,87 \%$ & $4,76 \%$ \\
\hline Conocimiento & 15 & $9,25 \%$ & $4,46 \%$ \\
\hline Sostenibilidad & 15 & 9,25 & $4,46 \%$ \\
\hline Vivienda & 16 & $9,87 \%$ & $4,76 \%$ \\
\hline Sector servicios & 3 & $1,85 \%$ & 0,89 \\
\hline Jóvenes & $0,61 \%$ & $0,29 \%$ \\
\hline Empleo joven & & & \\
\hline & & & \\
\hline
\end{tabular}

Fuente: elaboración propia. Es preciso puntualizar en relación a los porcentajes que no son excluyentes, es decir, en una misma parte del discurso se abordan simultáneamente distintos de los citados temas. Lo que explica que no puedan ser acumulados debido a esta cuestión del método.

4.1.2. La gestión de los temas: la configuración de la agenda a través del discurso

El término "issue" (tema), empleado en los estudios políticos anglosajones, hace referencia a una cuestión que es abordada en la agenda pública $\mathrm{y}$, por tanto, en el debate político. Es preciso distinguir la categoría "issue" y "problema", ya que un tema es susceptible de convertirse en un problema en determinadas condiciones y, por tanto, requerir una respuesta por parte de las instituciones (Lindblom y Woodhouse, 1993). En cambio, los temas representan los contenidos existentes en las distintas esferas y las 
cuestiones que tienen posibilidad de entrar en la agenda pública, es decir, son la materia prima desde la que los políticos perciben los problemas y adoptan decisiones para elaborar sus programas políticos y políticas públicas.

En este sentido, se ha efectuado una segunda cuantificación en función de los temas abordados en el área dedicada a la economía. De este modo, las categorías temáticas han sido seleccionadas en función a los principales contenidos de la política económica en España, considerando el contexto de la agenda económica española y el programa político del PSOE (Partido Socialista Obrero Español: Motivos para creer, Programa Electoral, 2008). Asimismo, se han incluido otros aspectos relacionados con la economía, tales como la tecnología, innovación, materia fiscal y financiación del gasto público, que son fundamentales en el análisis del discurso económico de un Estado Social de Derecho. A continuación, se presentan las categorías cuantificadas de acuerdo al número de proposiciones con respecto al total existentes en el espacio destinado a política económica.

La categoría de "política social", con un 52,46\%, representa la preocupación central en el discurso económico. Con ello, Zapatero demuestra la prioridad de los derechos y las ayudas sociales sobre la situación económica. De ahí, que este discurso demuestra el habitus del líder dispuesto a sacrificar la situación financiera para mantener un mínimo de bienestar social.

En segundo lugar, la "política presupuestaria" (32,09\%) constituye un elemento central en el debate. De este modo, el líder ha manifestado con el peso de este tema y el anterior que la estrategia para mantener los derechos sociales de los españoles y las españolas es el establecimiento de unas partidas presupuestarias adecuadas. Así, el debate sobre la asignación del gasto público representa una herramienta fundamental en la política económica.

En tercer lugar, el issue referente a "crecimiento económico" es el siguiente en importancia si se observa su peso en el discurso, con un $22,83 \%$ sobre el total del área económica. Lo que quiere decir, que el líder ha concedido importancia a la necesidad de hablar sobre los problemas de recesión que se derivan de la crisis económica. No obstante, la acentuada preocupación por los problemas del crecimiento y la ausencia de la palabra "crisis económica" manifiestan una incongruencia implícita en el discurso de Zapatero. La estrategia consiste en priorizar más la falta de crecimiento que las pérdidas derivadas de la crisis. Muy en esta línea, el área destinada a hablar de "recesión" dispone de un 19,13\% con respecto al total.

Posteriormente, tanto "ayudas sociales" como "productividad y competencia" con un valor del $20,96 \%$ son los siguientes temas tratados en la sesión de investidura. Las ayudas sociales ocupan un lugar considerable en las distintas actuaciones del ejecutivo atendiendo a la fragmentación de los colectivos sociales existentes. $\mathrm{Y}$ es que la productividad y la competencia son dos aspectos que se ven perjudicados por la denominada "desaceleración económica". De ahí, que el orador conceda cierta importancia a la necesidad de abordar medidas concretas.

Si se desciende, "empleo", "política fiscal" e "industria" son los siguientes temas en grado de espacio ocupado. De este modo, se observa como la situación de la crisis económica parece abordarse, desde el discurso, como una coyuntura que afecta en especial al empleo en el sector industrial. Por consiguiente, según el mensaje, los efectos de la crisis tendrían un peso menor en el ámbito de los servicios. Lo que se dirige en la línea del 14\% que ocupa la materia "Investigación y Desarrollo" tan necesaria para el cambio de modelo económico.

Las categorías de "sector servicios", "Sociedad de la Información y el Conocimiento", "vivienda", "sostenibilidad", "construcción" y "financiación de las autonomías" se sitúa por debajo del 10\% y encima del 5\%. Lo que representa unos temas accesorios a los anteriores, 
pero que requieren de la aplicación de unas medidas concretas. De ahí, que el líder tan sólo se limite a abordarlos para comentar las actuaciones que adoptará en cada uno de ellos. No obstante, es ilustrativo el peso de tan sólo un 8,64\% que el Presidente concede a la "construcción", que ha sido uno de los principales sectores afectados por la crisis.

Entre los temas a los que se les ha otorgado menor importancia con respecto a los demás, aquellos por debajo de un 5\%; se encuentran respectivamente "salarios", "inflación", "Ley de Dependencia", "jóvenes", "agricultura” y "empleo joven”. Así, la escasa atención prestada a la subida del Índice General de Precios contrasta con la importancia concedida a otros problemas como la "política social", "política presupuestaria" y "crecimiento económico".

\subsection{Una visión cualitativa del discurso destinado a economía}

El análisis cualitativo del discurso aporta una información a la que no se puede acceder desde los datos puramente cuantitativos. Por eso, se ha establecido una ordenación sistémica de la interrelación entre habitus y lenguaje, pues el análisis crítico del discurso es una herramienta flexible y carente de un marco disciplinar unitario (Van Dijk, 1999:23-36). De forma que el presente análisis lingüístico del Discurso de Investidura reúne una serie de conceptos propios de la sociolingüística y la metodología sociológica cualitativa. En el siguiente gráfico se presenta dicha interrelación.

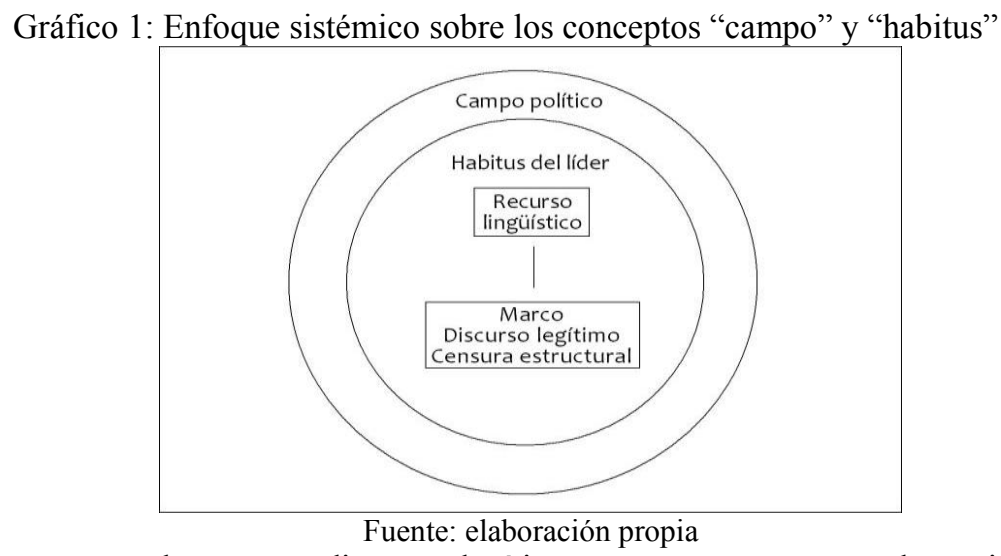

Los conceptos de marco, discurso legítimo y censura estructural servirán como términos metodológicos para traducir el empleo de los elementos lingüísticos en su relación con el campo y el habitus. Por ello, la primera labor consistirá en establecer el marco, el discurso legítimo y la censura estructural del Discurso de Investidura, para lo cual se ha de considerar sus condiciones de producción (Bourdieu, 1988; Martín, 1998). Condiciones que requieren un análisis de discurso legítimo y censura estructural en los textos anteriores y posteriores a la investidura, esto es, el Programa Electoral del PSOE en las Elecciones Generales de 2008 y el Plan E.

El primer paso antes de proceder a estudiar los recursos lingüísticos empleados por el orador pasaría por conocer el marco o los marcos en que se mueve el discurso (Collado, Jiménez y Molero, 2010:31-32). En concreto, el concepto de "marco" hace referencia a un conjunto de sub-universos dotados de existencia social propia que son definidos por la experiencia subjetiva y que disponen de sus propias leyes que les permiten establecer prioridades (Martín, 1998:61-62). Paralelamente al marco, los discursos encuentran 
"legitimidades" que aluden a los contenidos del mensaje ajustados a los valores y principios del rol asociado al orador; y una "censura estructural" definida por los límites que sesgan el discurso en determinados elementos, quedando éstos fuera del discurso por carecer de suficiente aceptación social.

\subsubsection{El framing en la agenda del PSOE para las elecciones de 2008}

La censura estructural estaría conformada por todos aquellos elementos semánticos que aluden a "crisis", "recesión económica" y cualquiera otra carga negativa que aludiera al pesimismo económico y que produzca inquietud social. Asimismo, el término "paro" apenas es empleado; muy al contrario, se alude más al "desempleo" que es mencionado en una docena de ocasiones. Manifiestamente, el fenómeno "inflación" está incluido entre las palabras prohibidas del mensaje, siendo apenas mencionado en dos momentos en el programa electoral. De esta forma, ninguno de los citados términos aparece mencionado en el programa electoral. Apenas en el área dedicada a mercados financieros se hace referencia a los "retos" de la globalización. Se ha de advertir que el programa electoral es un discurso de transición entre el Zapatero candidato a la Presidencia y el Zapatero Presidente de Gobierno. En otras palabras, representa una evaluación de la subjetividad que hace frente a situaciones con un contexto bien distinto. El discurso habla de los cambios en la interiorización y exteriorización de las propuestas y las ideas del líder.

Por su parte, el discurso legítimo defiende un modelo económico que mantenga la innovación, el conocimiento y la sostenibilidad como mínimo común. Las reglas de juego del marco socialista señalan que la búsqueda de la productividad y la competitividad pasarían por la formación de capital humano mediante la "Sociedad del Conocimiento y la Información". La remisión a los "retos" en el mercado financiero implica la futura legitimación de una "recesión económica" producida por la globalización y que más allá de las fronteras nacionales incide en la realidad interior.

\subsubsection{La subjetividad y las estrategias discursivas en el Discurso de Investidura}

Una vez conocido el marco, la censura estructural y el discurso legítimo del programa político del PSOE, se está en condiciones de estudiar los recursos lingüísticos empleados en el Discurso de Investidura. Así, estas estrategias lingüísticas se ponen en relación con el concepto "jugadas" ("moves") en el sentido de Goffman (Martín, 1998:57-71).

Para ello, se han seleccionado dos fragmentos de las áreas dedicadas a materia económica y social del Discurso de Investidura. De esta forma, el análisis se ciñe a un criterio temático por dos "issues" fundamentales en la coyuntura de principios del año 2009, como son la recesión económica y el proyecto económico de Zapatero. A continuación, se abordan las técnicas lingüísticas observadas en cada uno de ellos.

Fragmento I:

Las fortalezas de nuestra economía son un buen amortiguador, pero no son un muro que nos aísle de las turbulencias de la economía mundial. Vinculados como estamos con el resto de la economía global, la crisis que soporta Estados Unidos, las dificultades de los mercados financieros internacionales y la llamada crisis de liquidez, y la escalada de los precios del crudo, que se han multiplicado por cuatro en los últimos cuatro años, y de muchas materias primas y alimentos en los mercados internacionales dejan sentir sus efectos entre nosotros. Esos factores se conjugan en España con las dificultades del sector de la construcción de vivienda y con la acumulación a lo largo de los últimos lustros de algunos desequilibrios, 
fundamentalmente el déficit por cuenta corriente y el diferencial de inflación (Rodríguez Zapatero, 2008).

En la cita anterior se muestra una redundancia del mismo mensaje a lo largo de las dos primeras proposiciones. En tanto la primera implica una metáfora de la situación económica, en la segunda se procede a su concreción efectiva en los hechos. En la primera frase, se observa el empleo del eufemismo "turbulencias" para no hablar de "falta de dinero" y "caídas bursátiles" y en la última se refiere a "dificultades del sector de la construcción" en lugar de "crisis inmobiliaria". Asimismo, aparece un lenguaje técnico propio de la macroeconomía como son las construcciones "crisis de liquidez", "déficit por cuenta corriente" y "diferencial de inflación". En la segunda oración, se halla el recurso a la perífrasis "dejan sentir" en lugar de acortarlo en un verbo. En las tres oraciones se produce un alargamiento mediante el uso de subordinadas. De forma que el uso combinado de eufemismos, lenguaje técnico, giros perifrásticos y alargamientos configuran una apariencia críptica y cultista en el mensaje, en el cual predomina la función informativa.

Fragmento II:

“Ésa es, Señorías, mi idea de España: un país próspero, que genera la riqueza duradera que es la que brota de la inteligencia y no de la explotación de la naturaleza, ni de la mano de obra barata y descualificada; un país próspero y, además, un país decente, porque distribuye con equilibrio la riqueza que genera. Decente porque sus ciudadanos son solidarios con quienes más necesidades tienen; decente porque en él todos los ciudadanos y ciudadanas, de cualquier condición, cuentan con los mismos derechos, no sólo sobre el papel, sino en el día a día, y decente porque regula con rigor y trata con respeto a quienes vienen legalmente para labrar entre nosotros y junto a nosotros un futuro mejor para sí mismos y para sus hijos" (Rodríguez Zapatero, 2008).

Este fragmento representa la construcción subjetiva del proyecto de modelo económico y social que pretende implantar el líder. Es una trasposición de lo que siente, percibe y cree que debe traducir desde su interior hacia el exterior. Por lo que, el recurso a las anáforas "un país próspero" y "decente" es el sello distintivo de este párrafo, donde se enfatizan en un sintagma los objetivos políticos. Por otro lado, debido a que es la expresión de una idea que quiere plasmar mediante su gestión política, recurre al lenguaje positivo, en tanto que los verbos "genera", "distribuye", "son", "cuentan", "regula" y "tratan" son expresados en indicativo, en lugar del subjuntivo más propio para hablar de pensamientos, deseos y posibilidades. En otras palabras, para Zapatero su proyecto económico no es un simple pensamiento, sino una realidad efectiva que materializa mediante el modo indicativo. Estas técnicas suponen un reforzamiento de la función conativa que prevalece para convencer a su público.

Las palabras "decente", "próspero", "solidarios" y "derechos", formuladas con ensalmos, manifiestan una fuerte carga semántica donde se aprecian los matices ideológicos que Zapatero quiere marcar dentro de su grupo político y de cara a los demás. Así, esta sobrecarga de significados representa un lenguaje ideológico, pero ajustado a los cánones del "lenguaje políticamente correcto". También, en esta parte se muestra un alargamiento de las oraciones, pero mediante el uso de coordinadas. Por tanto, esta tiranía del lenguaje más correcto y menos hiriente esconde una suerte de negación que coincide con lo que se ha venido definiendo como "censura estructural" (Pano, 2011). 


\subsubsection{El framing del líder en el Plan E}

El marco en que se produce el Plan E es diferente al marco en que se produjo el programa electoral y el Discurso de Investidura de 2008 (Gobierno de España, 2009) este nuevo marco se reconoce que:

"La economía mundial atraviesa una crisis sin precedentes en la historia reciente. Una crisis que comenzó a mediados de 2007 como consecuencia de las llamadas hipotecas subprime en EE.UU., pero que se deterioró de forma profunda y acelerada a partir de septiembre de 2008 [...] La economía española ha sido especialmente sensible a este desfavorable contexto internacional [...] Como resultado de su dependencia exterior, la economía española, y en especial el mercado laboral, se ha deteriorado de forma muy importante a lo largo de 2008” (Gobierno de España, 2009).

Según el Gobierno de Zapatero:

"El Plan Español para el Estímulo de la Economía y el Empleo [Plan E] supone una movilización de recursos públicos sin precedentes" [en la historia de España]" (Gobierno de España, 2009).

Con esta afirmación el Presidente está reconociendo que España atraviesa una de las peores crisis económicas de su historia y que, por tanto, ante una situación extremadamente grave se han de hacer grandes esfuerzos de gasto público. Y esto se legitima por el hecho siguiente:

"Los tres años consecutivos de superávit presupuestario nos permiten ahora incurrir en déficit sin poner en riesgo la credibilidad de las finanzas públicas [...]" (Gobierno de España, 2009).

El principal objetivo para España en 2009 es la "recuperación del empleo". Sólo se cita una vez la palabra "paro" en el discurso de presentación del Plan E. El discurso legítimo, por tanto, es que el Gobierno hará todos los esfuerzos necesarios para recuperar el empleo que se está destruyendo (a lo largo del primer trimestre de 2009 los parados aumentaron en 469.000 personas). Por ello, se elude hablar del paro o desempleo y, más aún, de sus consecuencias reales sobre la ciudadanía española, asumiendo la grave "destrucción de empleo" que se produce. Por el contrario, se enfatiza los términos positivos de carácter técnico que se orientan a la recuperación económica, tales como: medidas de apoyo a las familias, protección social a las familias, medidas de apoyo a las empresas, facilitar el acceso al crédito de las empresas, medidas de fomento del empleo, medidas financieras y presupuestarias, modernización de la economía, recuperación de la productividad (Gobierno de España, 2009).

Asimismo, en la presentación del Plan E se evita hablar de las particulares condiciones estructurales de la economía española, hasta ahora bastante dependiente del sector de la construcción y de energías no renovables como el petróleo. Y en ningún momento se alude a las reformas estructurales que dichas condiciones económicas requerirían, por ejemplo: reforma estructural del mercado laboral o del sistema de la Seguridad Social (pensiones contributivas). Sin embargo, el Gobernador del Banco de España, Miguel Ángel Fernández Ordóñez, en abril de 2009 ya apuntó la necesidad de ciertas reformas estructurales en la economía española, suscitando una polémica con el gobierno de Rodríguez Zapatero. Supuestamente, la crisis se solucionaría con las medidas que entonces tomó el gobierno, que conllevaron un gasto público de "33.000 millones de euros en 2009 [en] apoyo a la obra pública” (Gobierno de España, 2009). 
En definitiva, el mensaje central del Plan E es que España saldrá de la crisis, gracias a las medidas adoptadas y a los esfuerzos conjuntos de todos los ciudadanos. Aunque dichos esfuerzos no se definen en los textos analizados.

\section{APUNTES CONSTRUCTIVISTAS SOBRE EL LÍDER Y SU DISCURSO ANTE LA CRISIS}

El Discurso de Investidura expresa un lenguaje político configurado por el recurso al eufemismo, los tecnicismos, el lenguaje políticamente correcto, las repeticiones (anáforas, catáforas, semánticas), alargamientos de las oraciones, perífrasis y el lenguaje positivo. En el análisis cuantitativo no se desprenden síntomas del lenguaje totalitario en el sentido de Bühler debido a la preeminencia de la función informativa, lo que manifiesta a un líder que ha pretendido explicar y gestionar la crisis en términos macroeconómicos y propios de la gestión pública. No obstante, el uso de las repeticiones, "en un país decente y próspero", y de ensalmos ("solidarios", "derechos", "decentes") demuestran una sobrecarga semántica. En cuanto a las funciones lingüísticas, cabe destacar el recurso mayoritario de la informativa y el uso combinado de la emotiva y de la conativa en aquellos "issues" no consensuados para obtener el apoyo de la audiencia. En otras palabras, la combinación de los sentimientos y los datos ha sido la estrategia para convencer al público.

En función del referido lenguaje político en la coyuntura de crisis, se observa que el habitus de Rodríguez Zapatero está definido por un carácter administrativo o burocrático con funciones representativas (Panebianco, 1990). Por ello, se observa el uso abundante de términos técnicos, cripticismos y cultismos. La otra cara de este habitus busca la emotividad en su público mediante la combinación de argumentos y sentimientos y el empleo de anáforas y metáforas. En relación al "campo", el lenguaje técnico y los sentimientos son las monedas de cambio para obtener el capital político en la cámara baja. Por tanto, el arma del lenguaje político no estaría dispuesta a ceder desde la posición de los derechos sociales, que son el discurso legítimo, pero atacaría con las argumentaciones y las emociones.

Por último, se observa una clara transformación del discurso legítimo y la censura estructural a lo largo del año 2008. El discurso económico legítimo sería hablar de "retos", pero evitar hablar de "crisis", "recesión", "paro" e "inflación" en el programa electoral del Partido Socialista de marzo de 2008. Así, se observa una evolución en las distintas acepciones que presenta el líder socialista (Pano, 2011:13). Tan sólo se permite la licencia de "desempleo" que es mencionada en una docena de ocasiones. Más tarde en el Discurso de Investidura, la censura estructural se flexibiliza y es posible mencionar "recesión económica", pero el concepto "crisis" es eludido. Las legitimidades residen en mantener los "derechos sociales" y el origen externo de las "turbulencias económicas". Finalmente, a principios del año 2009, el Plan E abre la puerta a la "crisis que comenzó a mediados de 2007”. El gran esfuerzo en "gasto público" e "inversión pública" constituyen el discurso legítimo para abordar la negativa situación de creciente destrucción de empleo. La irreversibilidad de la crisis y su planteamiento a largo plazo representa la censura estructural de esta última fase. En suma, el líder sostiene que la sociedad española podrá salir de la crisis mediante los esfuerzos conjuntos y la recuperación del empleo. 


\section{BIBLIOGRAFÍA}

ALVAR, M. (1987), El lenguaje político, Madrid, Instituto de Cooperación Iberoamericana.

ÁLVAREZ, J. L. (2011), "Después de Zapatero, el PSOE”, en El País, 2 de abril.

BERGER, P. y LUCKMANN, T. (1997), La construcción social de la realidad. Buenos Aires: Amorrortu.

BOIN, A. et al. (2007), La política de la gestión de crisis. El liderazgo público bajo presión. Madrid: Instituto Nacional de Administración Pública.

BOURDIEU, P. (1988), Cosas Dichas. Buenos Aires: Gedisa.

BUENO, G. (2006), Zapatero y el pensamiento Alicia. Un presidente en el País de las Maravillas.

Madrid: Temas de Hoy.

BURNS, J. M. (1978), Leadership. Nueva York: Harper and Row.

CAMPILLO, O. (2004), Zapatero: Presidente a la primera. Madrid: Esfera de los Libros.

CAMPMANY, J. (2005), El efecto ZP: mil días de campaña para llegar a la Moncloa. Barcelona: Planeta.

CHILTON, P. y SCHÄFFNER, C. (2002), Politics as Text and Talk: Analytical Approaches to Political Discourse. Amsterdam: John Benjamins.

COLLADO, F. y JIMÉNEZ, J. F. (2009), "El estudio del lenguaje político: de la vía lingüística a la sociológica", en Gallego, S. y Gómez, M. (coords.) Igualdad, desarrollo y cooperación. Madrid: Asociación Castellano-Manchega de Sociología, pp. 539-552.

COLLADO, F., JIMÉNEZ, J. F. y MOLERO, J.A. (2010), "El estudio del discurso político: una aproximación desde la sociología y la lingüística", en Cremades, R., González, C. y Guerrero, S. (coords.), Estudios actuales sobre lengua, literatura y su didáctica. Málaga: Universidad de Málaga, pp. 23-45.

DE MIGUEL, A. (1985), La perversión del lenguaje. Madrid: Espasa-Calpe.

DE TORO, S. (2007), Madera de Zapatero. Retrato de un Presidente. Madrid: RBA Libros.

DEL ÁGUILA R. y MONTORO, R. (1984), El discurso político de la transición española. Madrid: Siglo XXI.

ESTEFANÍA, J. (2009), "La Gran Recesión: segunda oleada”, en El País, 7 de noviembre.

FERNÁNDEZ, M. (1999), La lengua en la comunicación política: el discurso del poder. Madrid: Arco Libros.

GARCÍA ABAD, J. (2010), El Maquiavelo de León: cómo es en realidad Zapatero. Madrid: Esfera de los Libros.

GARCÍA AGUSTÍN Ó. (2006), "Republicanismo y el nuevo socialismo español de Rodríguez Zapatero", Sociedad y Discurso, n ${ }^{\circ} 9$.

GAREA, F. (2010), "El debate de la Nación más crítico", en El País, 15 de julio.

GOBIERNO DE ESPAÑA (2009), Plan E, Madrid, Presidencia del Gobierno, en http://www.plane.gob.es/que-es-el-plan-e/, visitado 20/09/2009.

GOFFMAN, E. (1974), Frame Analysis. An Essay on the Organization of Experience. Cambridge: Harvard University Press.

GONZÁLEZ, F. (2010), Mi idea de Europa. Barcelona: RBA Libros.

GRINT, K. (2005), "Problems, problems, problems: The social construction of Leadership", en Human Relations, $\mathrm{n}^{\mathrm{o}} 58$ (vol. 11), pp. 1467-1494.

GUITART, M.P. (2006), Lenguaje político y lenguaje políticamente correcto en España (con especial atención al discurso parlamentario), Valencia, Tesis doctoral, Universitat de València, en http://www.tesisenxarxa.net/TDX-0628106-110835/, visitado 21/09/2012.

JIMÉNEZ, J.F. (2009), "El liderazgo político de Felipe González en contexto", en Revista Sociedad y Utopía, nº 33, pp. 287-312.

- (2008), "Enfoque sociológico para el estudio del liderazgo político", en Revista Barataria. Revista Castellano-Manchega de Ciencias Sociales, ${ }^{\circ}$ 9, pp. 189-203.

JIMÉNEZ, J.F. y COLLADO, F. (2011), "Contexto político y semblanza biográfica de José Luis Rodríguez Zapatero”, Revista Espacios Públicos, n 31, pp. 136-157. 
LAKOFF, G. (2007), No pienses en un elefante: lenguaje y debate político. Madrid: Universidad Complutense de Madrid.

LAUSBERG, H. (1991), Manual de retórica literaria. Madrid: Gredos.

LINDBLOM, C. y WOODHOUSE, E. (1993), The policy-making process. New Jersey: Prentice-Hall.

LÓPEZ, A. (2000), Esencia y objeto de la retórica. Salamanca: Universidad de Salamanca.

MARTÍN, E. (2008), "El concepto de campo como herramienta metodológica", en Revista Española de Investigaciones Sociológicas (REIS), $\mathrm{n}^{\circ}$ 123, pp. 11-33.

- (1998), "Los decires y los haceres", en Papers, Revista de Sociología, no 56, pp. 57-71.

NÚÑEZ, E. A. y GUERRERO, S. (2002), El lenguaje político español. Madrid: Cátedra.

PANEBIANCO, A. (1990), Modelos de partido. Madrid: Alianza Universidad.

PANO, A. (2011), "La negación en el discurso político-económico de Zapatero", en Revista General de Derecho Público Comparado, ${ }^{\circ}$ 8, pp. 1-34.

PSOE (2008), Motivos para creer: programa electoral 2008. Madrid: PSOE.

ROBLES, A. (2009), "Élites, liderazgo y democracia. Liderazgo político y calidad de la democracia", en Vargas, S. (ed.), Liderazgo, políticas públicas y cambio organizacional: lecciones desde Iberoamérica. México: Editorial Porrua.

RODRÍGUEZ ZAPATERO, J. L. (2008), Discurso de José Luis Rodríguez Zapatero en la Sesión de Investidura como Presidente del Gobierno, Madrid, Congreso de los Diputados.

VALENZUELA, J. (2007), Viajando con ZP. Madrid: Debate.

VAN DIJK, T. A. (1999), "El análisis crítico del discurso", en Anthropos, n 186, pp. 23-36.

\section{Breve currículo:}

\section{Francisco Collado Campaña}

Licenciado en Periodismo por la Universidad de Málaga, y Licenciado en Ciencias Políticas y de la Administración por la Universidad Pablo de Olavide (Sevilla). Sus líneas de investigación son liderazgo y élites políticas, comunicación política y teoría política, habiendo publicado varios trabajos sobre los usos del lenguaje en la clase política. Asimismo, ha participado en varios proyectos de investigación nacionales sobre sociología y ciencia política. Actualmente realiza su Trabajo Fin de Máster sobre liderazgo y élites locales en el Máster 'Política y Democracia' de la UNED.

\section{José Francisco Jiménez Díaz}

Doctor en Sociología por la Universidad de Granada y Profesor de Ciencia Política y de la Administración en la Universidad Pablo de Olavide (Sevilla). Actualmente, sus temas de investigación son liderazgo político democrático, teorías políticas normativas y efectos locales de la globalización. Sobre estos temas ha publicado artículos en revistas de ciencias sociales, libros y capítulos de libro. Durante los últimos cinco años ha participado en varios proyectos de investigación $\mathrm{I}+\mathrm{D}$, financiados por el Ministerio de Educación y la Junta de Andalucía. Además, ha realizado estancias de investigación posdoctorales en la London School of Economics and Political Science (LSE) y en el Instituto Superior de Ciências Sociais e Políticas de la Universidad Técnica de Lisboa (ISCSP). 